\title{
Artificial neural network modeling of $p$-cresol photodegradation
}

\author{
Yadollah Abdollahi i* Azmi Zakaria ${ }^{*}$, Mina Abbasiyannejad ${ }^{2}$, Hamid Reza Fard Masoumi ${ }^{3}$, \\ Mansour Ghaffari Moghaddam ${ }^{4}$, Khamirul Amin Matori ${ }^{1}$, Hossein Jahangirian ${ }^{5}$ and Ashkan Keshavarzi ${ }^{6}$
}

\begin{abstract}
Background: The complexity of reactions and kinetic is the current problem of photodegradation processes. Recently, artificial neural networks have been widely used to solve the problems because of their reliable, robust, and salient characteristics in capturing the non-linear relationships between variables in complex systems. In this study, an artificial neural network was applied for modeling $p$-cresol photodegradation. To optimize the network, the independent variables including irradiation time, $\mathrm{pH}$, photocatalyst amount and concentration of $p$-cresol were used as the input parameters, while the photodegradation\% was selected as output. The photodegradation\% was obtained from the performance of the experimental design of the variables under UV irradiation. The network was trained by Quick propagation (QP) and the other three algorithms as a model. To determine the number of hidden layer nodes in the model, the root mean squared error of testing set was minimized. After minimizing the error, the topologies of the algorithms were compared by coefficient of determination and absolute average deviation.
\end{abstract}

Results: The comparison indicated that the Quick propagation algorithm had minimum root mean squared error, 1.3995, absolute average deviation, 3.0478, and maximum coefficient of determination, 0.9752 , for the testing data set. The validation test results of the artificial neural network based on QP indicated that the root mean squared error was 4.11, absolute average deviation was 8.071 and the maximum coefficient of determination was 0.97 .

Conclusion: Artificial neural network based on Quick propagation algorithm with topology 4-10-1 gave the best performance in this study.

Keywords: Photodegradation, ANN-modeling, p-cresol, ZnO, UV-irradiation, Photocatalyst

\section{Background}

Environmental pollution on a global scale has drawn the attention of scientists to the vital need for friendly chemically clean processes. Phenolic compounds such as cresols are widely used in manufacturing products including cresol-based resin, herbicides, pharmaceuticals, surfactants and petrochemical [1]. P-cresol, water solubility above $21.5 \mathrm{~g} \mathrm{~L}^{-1}$ at $25^{\circ} \mathrm{C}$, has been listed as a persistent priority, toxic chemical and the quantitative structureactivity relationship which indicates a significant threat to the environment [2-5]. Recently, advanced oxidation processes (AOPs) have been used as one of the practical technologies for the removal of the persistent pollutants

\footnotetext{
* Correspondence: yadollahabdolla@upm.edu.my; azmizak@gmail.com 'Material Synthesis and Characterization Laboratory, Institute of Advanced Technology, Universiti Putra Malaysia, 43400 UPM Serdang, Selangor, Malaysia

Full list of author information is available at the end of the article
}

[6-8]. Among the various AOPs, zinc oxide $(\mathrm{ZnO})$ as heterogeneous photocatalysis showed great photodegradation due to its ability to destroy a wide range of the pollutants at ambient temperature and pressure, without generation of harmful by-products [5,9-13]. In the photodegradation process, the main effective operational parameters such as irradiation time, $\mathrm{pH}$, photocatalyst amount and concentration of the pollutants were investigated under ultra violet (UV) and visible-light irradiation [13-17]. However, the complexities of the parameters behavior in the radiant energy balance, the spatial distribution of the absorbed radiation, mass transfer, and mechanisms of the photochemical degradation, cause misinterpretation of results. In addition, the kinetic of the photodegradation is quite difficult to determine [18]. The complexities have been big challenges for the traditional methods such as one-variable-at a time. The methods have been carried out by varying one parameter while fixing other

\section{(Chemistry Central}


variables constant. Since the variables are not completely independent of each other during the process, it might have adverse effects on the yield of the photodegradation $[13,15]$. On the other hand, the multivariate methods such as response surface methodology (RSM) consider the effect of the variables during the performance simultaneously, which could be a promising view [16]. However, the methods consider only two variables at a time, which could be a big disadvantage for the complex system with more than two variables. Furthermore, the method is involved with the complicated statistical calculation such as fitting process and regression analysis [17,19]. More recently, artificial neural networks (ANN) have been widely used for modeling chemical reaction processes [20-23]. The models possessed reliable, robust, and salient characteristics in capturing the non-linear relationships between variables in the complex system. Therefore, the successful photodegradation of many environmental organic pollutants such as ethylene-diamine-tetra-acetic acid [24], nitrogen oxides [25], nitrilotriacetic acid [26], 2,4-dihydroxybenzoic acid [27] and decolorization of CI Acid Blue 9 [28] was studied by the ANN. As observed, the ANNs simulated the behavior of the complex reaction system by using different algorithms such as Quick propagation (QP), Incremental backpropagation (IBP), Batch backpropagation (BBP) and Levenberg- Marquardt (LM) algorithm [20]. Among them, the backpropagation was a popular algorithm. Since the results of the photocatalytic processes under different conditions were estimated free of the complexities. In this work, the development of a multilayer feed-forward neural network model was used to predict the photodegradation\% of $p$-cresol by $\mathrm{ZnO}$ under UV irradiation. To optimize the modeling, the results of the algorithms were compared by minimized root mean squared error (RMSE) and the percentage of absolute average deviation (AAD) while the coefficient of determination $\left(R^{2}\right)$ was maximized.

\section{Experiment}

\section{Materials and methods}

P-cresol (99.5\%, fluka), $\mathrm{NaOH}$ (99\% Merck), $\mathrm{H}_{2} \mathrm{SO}_{4}$ (95\%-97\%) and other required chemicals were of reagent grade, obtained from Merck and were used without further purification. The $\mathrm{ZnO}$ (99\%, merck) has a surface area of $3.3 \mathrm{~m}^{2} / \mathrm{g}$ measured by static BET using thermo finnigan sorptomatic 1990 series analyzer. The particle size of $\mathrm{ZnO}$ recorded on nanophox facility was $0.4-0.5 \mu \mathrm{m}$. Band gap measured using PerkinElmer Lambda $35 \mathrm{UV} /$ Vis/NIR was $3.02 \mathrm{eV}$. In all photocatalytic experiments, a litter of mixture $\mathrm{ZnO}$ with known quantities and $p$-cresol was irradiated for an appropriate time. Photocatalytic experiments were performed in a non-continuous mode (batch) binary reactor fitted with $6 \mathrm{~W}$ UV-A lamp [15]. The mixture was magnetically stirred $(200 \mathrm{rpm})$ to maintain even distribution of suspension throughout the reactor and to eliminate mass gradient. Air was blown into the reaction solution using an air pump at a flow rate of $150 \mathrm{~L} / \mathrm{h}$ to make the produced gas volatile $\left(\mathrm{CO}_{2}\right)$, increase solution fluidization and finally to make oxygen accessible. Flowing cooled water into the binary cylinder kept the temperature at around $25^{\circ} \mathrm{C}$. At specific time intervals, samples were drawn from the bulk solution. The samples were filtered through a $0.45 \mu \mathrm{m}$ polytetrafluroethylene (PTFE) membrane. In order to compare the efficiency of the photocatalytic degradation of $p$-cresol, the filtrates were analyzed by UV-Visible spectrometry (Shimadzu, UV-1650pc) at the maximum absorption wavelength of $p$-cresol ( $277 \mathrm{~nm})$. It should be mentioned that the small positive error of UV-Visible spectrometry in comparison with HPLC was ignored in this paper (results not shown). The percentage of photocatalytic degradation of $p$-cresol was calculated using Equation (1).

$$
\text { Photodegradation } \%=\frac{\left(C_{0}-C\right)}{C_{0}} \times 100
$$

where $\mathrm{C}_{0}=$ initial concentration of $p$-cresol, $\mathrm{C}=$ concentration of $p$-cresol after photo irradiation. All photocatalytic degradation experiments were carried out in duplicate. The initial photocatalytic degradation was investigated in the dark, in the absence of the photocatalyst and at normal pH (7.5). Results showed only $6 \%$ and 7\% of $p$-cresol was photolysed and adsorbed by the UV irradiation and the photocatalyst surface respectively [29].

\section{Experimental design}

The modeling of the photodegradation was carried out by NeuralPower software version 2.5 which is used in several researches [30,31]. To design the experiments, irradiation time, $\mathrm{pH}$, amount of photocatalyst and $p$-cresol concentration were selected as independent variables (inputs); while photodegradation (\%) was selected as the dependent variable (output). The design was performed in the laboratory to obtain the actual responses. The experimental values were then used for ANN modeling. The data were randomly divided into three sets as training, testing and validation data (Table 1) using the option available in the software. The training and testing data were used to compute and ensure robustness of the network parameters, respectively. The testing stage was also utilized to avoid over fitting by using control errors [32]. To assess the predictive ability of the generated model, validation data were considered [21]. The data consisted of six additional experiments which were in the range of values given for ANN modeling and excluded from training and testing (Table 1). 
Table 1 The independent variables as input, actual and predicated of $p$-cresol photodegradation as output for training, testing and validation set

\begin{tabular}{|c|c|c|c|c|c|c|}
\hline \multirow[t]{2}{*}{ Run } & \multirow{2}{*}{$\begin{array}{l}\text { Irradiation } \\
\text { time (min) }\end{array}$} & \multirow[t]{2}{*}{$\mathrm{pH}$} & \multirow{2}{*}{$\begin{array}{l}\text { Photocatalyst } \\
\text { (g) }\end{array}$} & \multirow{2}{*}{$\begin{array}{l}\text { P-cresol } \\
\text { (ppm) }\end{array}$} & \multicolumn{2}{|c|}{ Photodegradation (\%) } \\
\hline & & & & & Actual & Predicted \\
\hline \multicolumn{7}{|c|}{ Training Data } \\
\hline 1 & 300 & 6 & 2 & 100 & 62.479 & 63.176 \\
\hline 2 & 240 & 7.5 & 1.5 & 125 & 53.094 & 53.327 \\
\hline 3 & 180 & 9 & 2 & 100 & 40.124 & 39.348 \\
\hline 4 & 300 & 9 & 2 & 100 & 74.538 & 74.800 \\
\hline 5 & 120 & 7.5 & 1.5 & 75 & 48.465 & 49.289 \\
\hline 6 & 360 & 7.5 & 1.5 & 75 & 92.229 & 93.719 \\
\hline 7 & 180 & 6 & 1 & 50 & 45.636 & 45.549 \\
\hline 8 & 300 & 6 & 1 & 50 & 65.062 & 65.131 \\
\hline 9 & 180 & 9 & 1 & 50 & 69.848 & 69.680 \\
\hline 10 & 240 & 7.5 & 1.5 & 25 & 95.866 & 96.360 \\
\hline 11 & 180 & 9 & 1 & 100 & 57.887 & 57.755 \\
\hline 12 & 300 & 6 & 2 & 50 & 92.261 & 91.860 \\
\hline 13 & 180 & 6 & 1 & 100 & 36.513 & 37.256 \\
\hline 14 & 300 & 6 & 1 & 100 & 55.227 & 54.659 \\
\hline 15 & 180 & 6 & 2 & 50 & 63.546 & 63.619 \\
\hline 16 & 180 & 9 & 2 & 50 & 75.796 & 76.247 \\
\hline 17 & 240 & 7.5 & 0.5 & 75 & 70.055 & 70.197 \\
\hline 18 & 240 & 7.5 & 2.5 & 75 & 84.811 & 85.001 \\
\hline 19 & 300 & 9 & 1 & 100 & 78.207 & 78.287 \\
\hline 20 & 240 & 4.5 & 1.5 & 75 & 25.717 & 25.788 \\
\hline 21 & 240 & 10.5 & 1.5 & 75 & 55.993 & 56.588 \\
\hline 22 & 180 & 6 & 2 & 100 & 35.462 & 34.380 \\
\hline 23 & 300 & 9 & 1 & 50 & 85.148 & 84.930 \\
\hline 24 & 300 & 9 & 2 & 50 & 96.684 & 96.131 \\
\hline 25 & 240 & 7.5 & 1.5 & 75 & 92.555 & 89.420 \\
\hline \multicolumn{7}{|c|}{ Testing Data } \\
\hline 26 & 150 & 7 & 1.5 & 75 & 58.750 & 58.462 \\
\hline 27 & 210 & 8 & 1.5 & 50 & 85.330 & 91.185 \\
\hline 28 & 240 & 7.5 & 1.5 & 50 & 98.000 & 96.208 \\
\hline 29 & 180 & 7.49 & 1.5 & 75 & 68.802 & 71.687 \\
\hline 30 & 240 & 7.5 & 1 & 75 & 92.083 & 88.658 \\
\hline 31 & 270 & 8 & 1.5 & 75 & 88.967 & 90.029 \\
\hline
\end{tabular}

\section{Validation Data}

\begin{tabular}{ccccccc}
32 & 180 & 7 & 1.5 & 75 & 65.778 & 74.244 \\
33 & 240 & 7.5 & 1.5 & 50 & 92.716 & 97.141 \\
34 & 180 & 8 & 1.5 & 75 & 68.218 & 78.871 \\
35 & 240 & 7.49 & 1 & 60 & 81.217 & 87.489 \\
36 & 180 & 7.49 & 1.5 & 50 & 85.233 & 92.214 \\
37 & 210 & 7.49 & 1.5 & 75 & 81.474 & 87.439 \\
38 & 240 & 7.5 & 1.5 & 75 & 88.000 & 91.143 \\
\hline
\end{tabular}

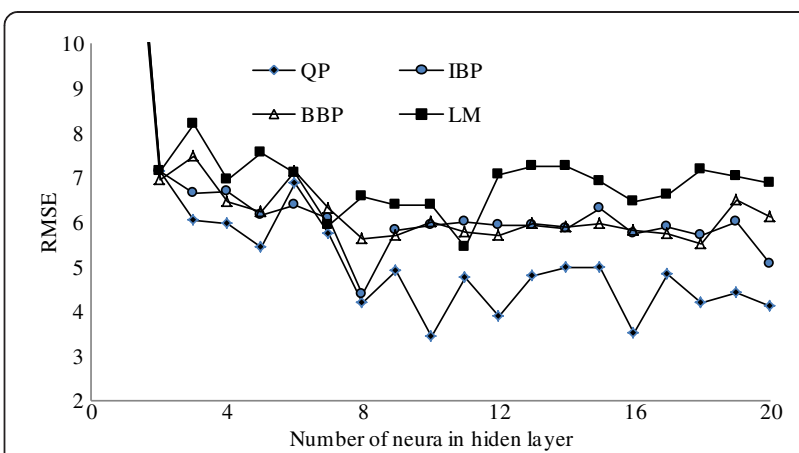

Figure 1 The performance of the network at different hidden neurons using, Incremental backpropagation algorithm (IBP), Batch backpropagation algorithm (BBP) and Quick propagation algorithm (QP).

\section{The ANN description}

Generally, ANNs are mathematical models, which consist of connected units (neurons/nodes) in different layers. The models are usually used to infer a function from observations of a particular process. The network consists of different layers which are inter-connected by parallel nodes. The nodes are simple artificial neurons, which mimic a biological neural network. The inter-connections of nodes are qualified by the associated weights. The layers include first layer (input), which sends data via the weights to the nodes of the second layer (hidden layer), and then to the third layer (output) [33]. Multi-layer perceptron is a class of networks, which consists of multiple layers with computational units. The units are usually interconnected in a non-directed cycle way such as feed-forward neural network. In the network, the hidden layers can be more than one layer, but a single hidden layer is universally suggested. The number of hidden nodes is obtained by trial and error calculation, which is examined from 1 to ' $n$ ' nodes. The inter-connection type of layers is multilayer normal feed-forward [33]. In the net, all the nodes of a particular layer are connected to all the nodes of the next layer. In addition, the inputs for hidden and output layers are calculated by performing a weighted summation of all the inputs received from the former layer. The weighted sum of the inputs is transferred to the hidden nodes, where it is transformed using a

Table 2 Statistical measures and performances of four learning algorithms on the photodegradation of $p$-cresol in suspension ZnO

\begin{tabular}{lcccc}
\hline Learning algorithm & \multirow{2}{*}{$\begin{array}{c}\text { The } \\
\text { architecture }\end{array}$} & \multicolumn{3}{c}{ Testing data } \\
\cline { 3 - 5 } & & RMSE & $\mathbf{R}^{\mathbf{2}}$ & AAD\% \\
\hline Quick Propagation (QP) & $4-10-1$ & 1.399 & 0.975 & 3.048 \\
Incremental Backpropagation (IBP) & $4-8-1$ & 1.792 & 0.965 & 4.184 \\
Batch Backpropagation (BBP) & $4-18-1$ & 2.254 & 0.937 & 5.307 \\
Levenberg-Marquardt (LM) & $4-11-1$ & 2.221 & 0.942 & 5.579 \\
\hline
\end{tabular}






(a)

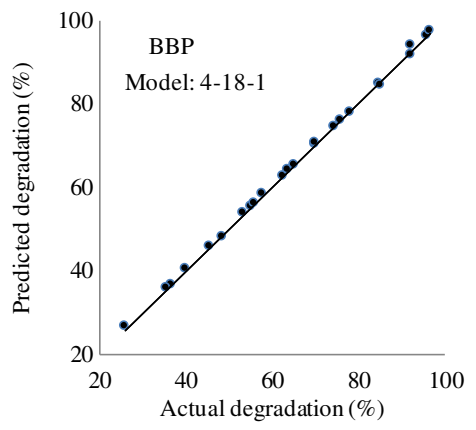

(c)



(b)

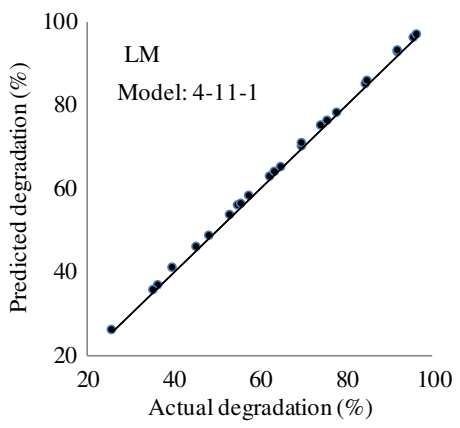

(d)

Figure 2 The scatter plots of ANN predicted photodegradation \% versus actual photodegradation \% for training data set. (a) Quick propagation (QP) algorithm, (b) Incremental backpropagation (IBP) algorithm, (c) Batch backpropagation (BBP) algorithm and (d) LevenbergMarquardt (LM) backpropagation algorithm.

transfer function [34]. The output of hidden nodes in turn, acts as inputs to output nodes where it undergoes similar or different transformation. In this case, the ANN was trained by using the learning algorithmic program which included QP, IBP, BBP and LM algorithm [20] while the connection types were the multilayer feedforward. The transfer function was the logarithmic sigmoid for both hidden and output layers [35]. Since the sigmoidal function is bounded between 0 and 1 the input and output data is normalized to the range by the software scaling. The scaled data are passed into the input layer, propagated to hidden layer to reach to the output layer of the network. The number of hidden node is obtained by trial and error calculation. The nodes as output layer

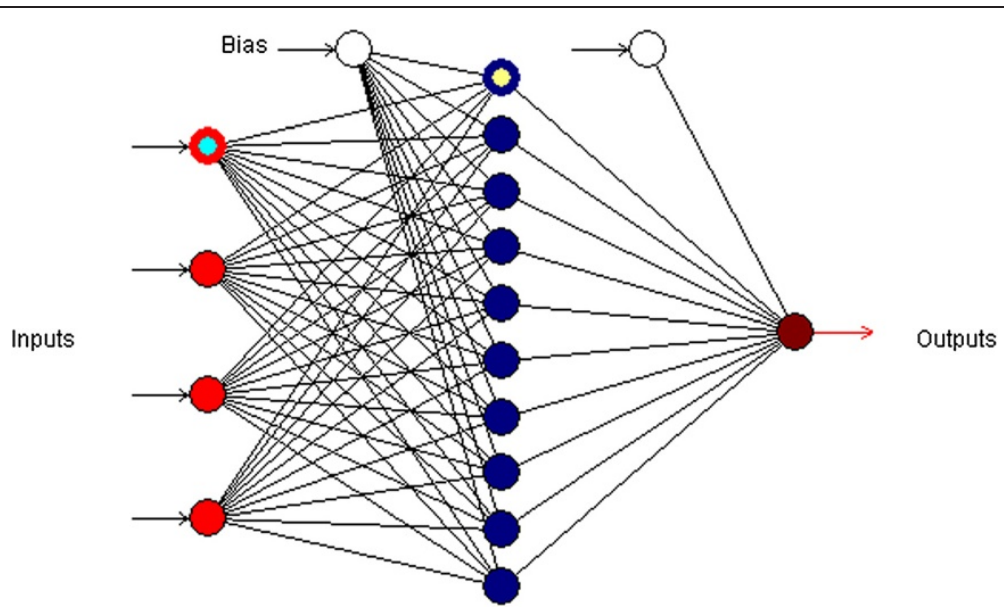

Figure 3 The multilayer feed-forward perceptron (MLP) network for quick propagation (QP) algorithm, the model consists of four inputs, one hidden layer with ten neurons and one output. 


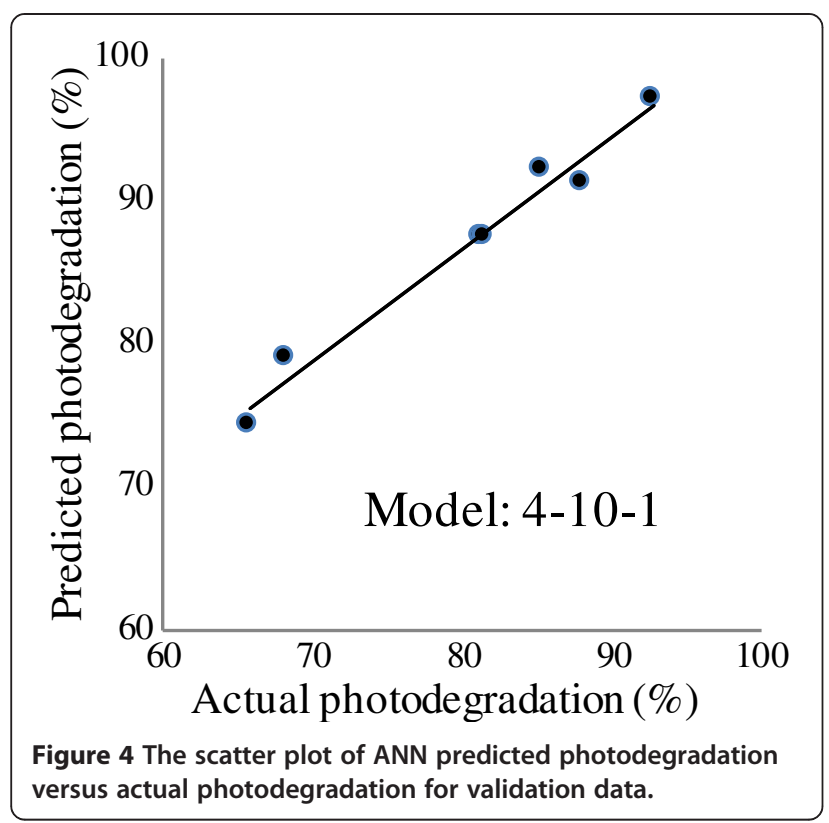

firstly acts as a summing junction which combines and modifies the inputs from the previous layer using the equation (2) [24],

$$
y_{i}=\sum_{j=1}^{i} x_{i} w_{i j}+b_{j}
$$

where ' $y$ ' is the net input to node ' $j$ ' in hidden or output layer, $x_{i}$ are the inputs to node $j$ (or outputs of previous layer). The ' $\mathrm{w}_{\mathrm{ij}}$ ' is the weights which represents the strength of the connection between the ' $i{ }^{\text {th }}$ node and ' $j$ th node. The ' $i$ ' is the number of nodes and ' $b_{j}$ ' is the bias associates with node ' $j$ '. Moreover, the learning rate and momentum coefficient for the networks are chosen by the software default values [33]. The results of the process are

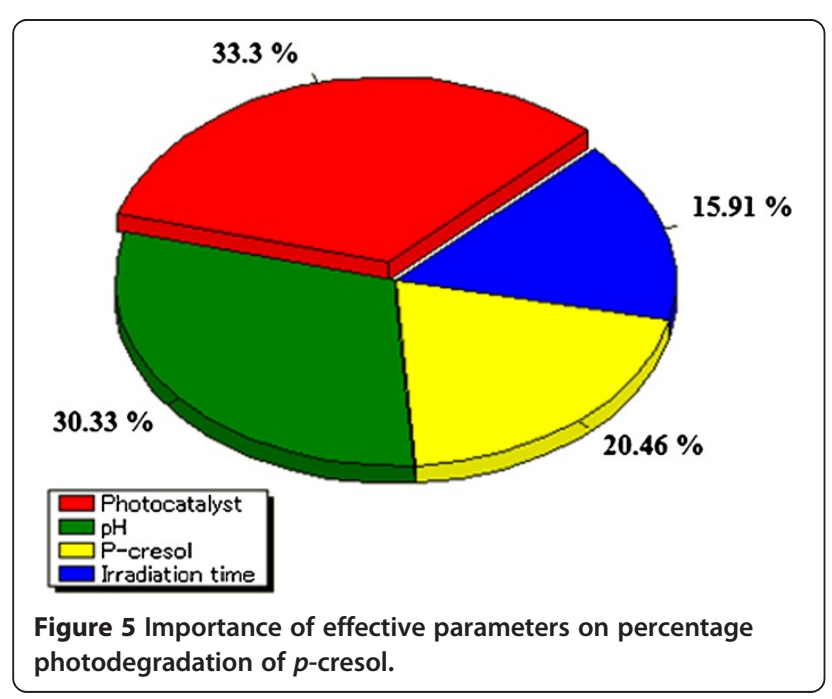

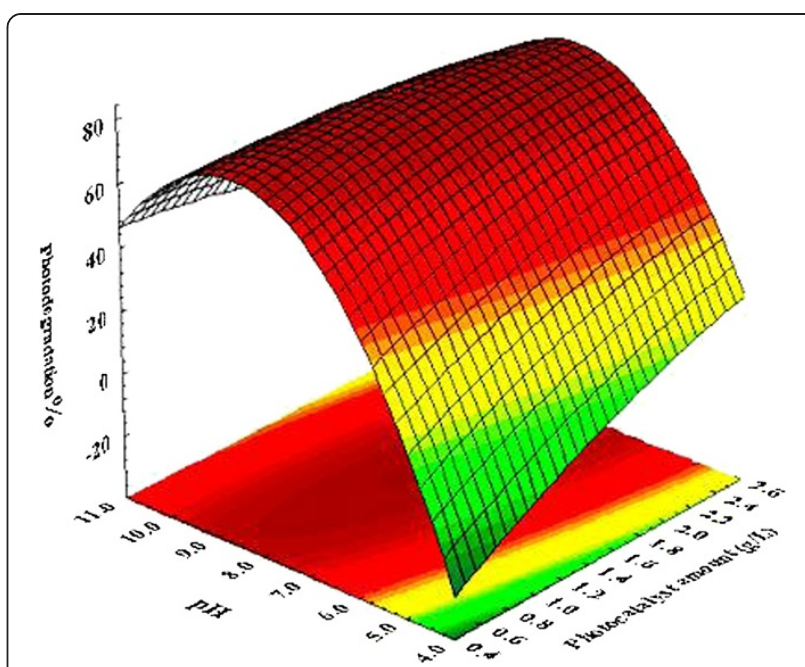

Figure 6 Three dimensional plots of photocatalyst and $\mathrm{pH}$ effect on the photodegradation percentage. The other variables were kept constant.

appeared as RMSE (Eq. 3) which is based on the difference between actual and predicted values (Table 1).

$$
\text { RMSE }=\left(\frac{1}{n} \sum_{i=1}^{n}\left(y_{i}-y_{d i}\right)^{2}\right)^{\frac{1}{2}}
$$

where ' $\mathrm{n}$ ' is the number of points, ' $\mathrm{y}_{\mathrm{i}}$ ' is the predicted values and ' $y_{\mathrm{di}}$ ' is the actual values. The minimum RMSE of the examined nodes demonstrate the desirable networks. Furthermore, the performance of the ANN models was assessed on the basis of the coefficient of determination $\left(\mathrm{R}^{2}\right)$ and the percentage of absolute average deviation (AAD) between the models predicted-actual values of the network. The $\mathrm{R}^{2}$ and AAD are calculated as equations (4 and 5),

$$
R^{2}=1-\frac{\sum_{i=1}^{n}\left(y_{i}-y_{d i}\right)^{2}}{\sum_{i=1}^{n}\left(y_{d i}-y_{m}\right)^{2}}
$$

Table 3 Range and relative significance of the ANN input variables used in this work

\begin{tabular}{cccc}
\hline Input variables & Units & Range & Importance (\%) \\
\hline Irradiation time & min & $120-360$ & 16.34 \\
pH & - & $4.5-10.5$ & 30.31 \\
Photocatalyst amount & $\mathrm{g} \mathrm{L}^{-1}$ & $0.5-2.5$ & 33.26 \\
-cresol concentration & $\mathrm{mg} \mathrm{L}^{-1}$ & $25-125$ & 20.09 \\
\hline
\end{tabular}




$$
A A D=\left\{\left[\sum_{i=1}^{n}\left(\left|y_{i}-y_{d i}\right| / y_{d i}\right)\right] / n\right\}
$$

where ' $\mathrm{n}$ ' is the number of points, ' $\mathrm{y}_{\mathrm{i}}$ ' is the predicted value, ' $y_{d i}$ ' is the actual value, and ' $y_{m}$ ' is the average of the actual values. Therefore, the appropriate topologies are determined by minimum RMSE and ADD while the $\mathrm{R}^{2}$ is at maximum value.

\section{Results and discussion \\ The ANN model training}

In order to determine the optimum number of neurons in the hidden layer, a series of topologies was examined, in which the number of neurons was varied from 1 to 20 . For instance, each topology was repeated 15 times to avoid random correlation due to the random initialization of the weights [36]. The RMSE was used as the error function. Moreover, the $\mathrm{R}^{2}$ and the AAD were used as a measure of the predictive ability of the network. Decision on the optimum topology was based on the minimum error of testing set values. These topologies have the lowest RMSE for the training and testing sets. Figure 1 illustrates the performance of the network for testing data versus of the number of neurons in the hidden layer using IBP, QP, BBP and LM algorithms. According to the RMSE the network with 8 hidden neurons produced the best performances when IBP algorithm was employed. Similarly, the best results were obtained with 10 hidden neurons using QP algorithm. The network with 18 hidden neurons produced the best results for BBP algorithm and best results obtained with 11 hidden neurons using LM algorithm. Therefore, the optimum topologies of the networks were 4-8-1, 4-10-1, 4-18-1 and 4-11-1 for IBP QP, BBP and LM algorithms respectively.

\section{Selection neural network model}

Table 2 summarized the results of RMSE, $\mathrm{R}^{2}$ and AAD for the used algorithms in testing set. As shown, QP was at minimum of RMSE and AAD while, its $R^{2}$ was at the highest value in comparison with the other algorithms. Therefore, the performance of QP with 4-10-1 topology was more effective than IBP, BBP and LM algorithms.

Table 1 presents the predicted values of the photodegradation for QP, IBB, BBP and LM algorithms. Figure 2 shows the predicted values versus the photodegradation actual values for the training set. As the comparison of the scatter plots demonstrates, the QP predicted model was well fitted to the actual values $\left(R^{2}=0.9997\right)$. Therefore, the QP with 4-10-1 topology (Figure 3) was considered as efficient model training for the photodegradation.

\section{Model validation}

The predictive ability of the generated model (4-10-1) was validated using a series of data which was excluded from training and testing data set (Table 1). Figure 4 presents the prediction versus actual of the photodegradation which was obtained in laboratory. As illustrated, the RMSE was 2.31; the $\mathrm{R}^{2}$ was 0.98 and the AAD\% was 4.4 which indicated the great predictive accuracy of the model.

\section{The importance}

Figure 5 demonstrates the importance of effective parameters on the photodegradation as an output of the model. As shown the importance values of the parameters was photocatalyst amount $>\mathrm{pH}>\mathrm{p}$-cresol concentration $>$ irradiation time in the selected range of the variables (Table 3). For further information, the optimum amounts of the importance factors, which were photocatalyst and $\mathrm{pH}$, presented in Figure 6.

\section{Conclusion}

The modelling of $p$-cresol photodegradation was carried out by the ANN. The photodegradation was performed in $\mathrm{ZnO}$ suspension and under UV irradiation. The model contained input, hidden and output layers. The inputs included irradiation time, $\mathrm{pH}$, photocatalyst amount and concentration of $p$-cresol while the photodegradation \% was the output. To obtain the optimum model, ANN was trained by QP, IBP, BBP and LM algorithms. The minimum RMSE values through the repeating data were used as indicator to determine the number of nodes in the hidden layer for each algorithm. According to the minimum RMSE, the 4-10-1, 4-8-1, 4-18-1 and 4-11-1 topologies were selected for the algorithms. To compare the optimized topologies, the RMSE was used as the error function; $\mathrm{R}^{2}$ and ADD employed as an index of the network predictive ability. The comparison of the algorithm indicated that the QP had minimum RMSE, 1.3995, AAD\%, 3.05, and maximum $\mathrm{R}^{2}, 0.98$, for the testing set. Furthermore, the results of QP validation were 0.97, 2.3 and 4.4 for $\mathrm{R}^{2}$, RMSE and AAD\% respectively. In conclusion, the QP gave the best performances and was selected as the process' model.

\section{Competing interests}

Are there any non-financial competing interests (political, personal, religious, ideological, academic, intellectual, commercial or any other) to declare in relation to this manuscript? The authors declare that they have no competing interests.

\section{Authors' contributions}

YA (AB, JY, MT, ES) AZ (FG) MA (MT, FG), HRFM (ES), MGM (ES), KAM (FG) HJ (FG), AK (MT). AB carried out the catalyst design and ligand screening studies. JY carried out the synthesis, purification and characterization of the compounds. MT carried out the computational experiments. FG conceived of the study, and participated in its design and coordination and helped to draft the manuscript. All authors read and approved the final manuscript. 


\section{Acknowledgements}

The authors would like to express acknowledgement with thanks to the Ministry of Higher Education Malaysia for this project grant under Research University Grant Scheme (RUGS) of Project No. 05-02-12-1878.

\section{Author details}

${ }^{1}$ Material Synthesis and Characterization Laboratory, Institute of Advanced Technology, Universiti Putra Malaysia, 43400 UPM Serdang, Selangor, Malaysia. ${ }^{2}$ English Department, Faculty of Modern Languages and Communication, Universiti Putra Malaysia, 43400 UPM Serdang, Selangor, Malaysia. ${ }^{3}$ Department of Chemistry, Faculty of Science, Universiti Putra Malaysia, 43400 UPM Serdang, Selangor, Malaysia. ${ }^{4}$ Department of Chemistry, Faculty of Science, University of Zabol, Zabol, Iran. ${ }^{5}$ Department of Chemical and Environmental Engineering, Faculty of Engineering, Universiti Putra Malaysia, 43400 UPM Serdang, Selangor, Malaysia. ${ }^{6}$ Otto-Schott-Institut, Jena University, Fraunhoferstr. 6, 07743 Jena, Germany.

Received: 17 March 2013 Accepted: 28 May 2013

Published: 3 June 2013

\section{References}

1. Abdollahi Y, Abdullah AH, Zainal Z, Yusof NA: Photodegradation of m-cresol by Zinc Oxide under Visible-light Irradiation. Int J Chem 2011, 3(3):31-43.

2. Callahan M, Slimak M, Gbel N, May I, Fowler C, Freed R, Jennings P, Dupree R, Whitemore F, Maestri B: Water Related Environmental Fate of 120 Priority Pollutants. In Report No. EPA-44014-79-029a, b, United States Environmental Protection Agency. Washington, DC: NTIS; 1979.

3. Cooper $\mathrm{E}$ : On the relations of phenol and meta-cresol to proteins; a contribution to our knowledge of the mechanism of disinfection. Biochem J 1912, 6(4):362-387.

4. Kavitha $V$, Palanivelu K: Destruction of cresols by Fenton oxidation process. Water Res 2005, 39(13):3062-3072.

5. Pardeshi SK, Patil AB: A simple route for photocatalytic degradation of phenol in aqueous zinc oxide suspension using solar energy. Solar Energy 2008, 82(8):700-705.

6. Marcì G, Addamo M, Augugliaro V, Coluccia S, García-López E, Loddo V, Martra G, Palmisano L, Schiavello M: Photocatalytic oxidation of toluene on irradiated $\mathrm{TiO}_{2}$ : comparison of degradation performance in humidified air, in water and in water containing a zwitterionic surfactant. J Photochem Photobiol Chem 2003, 160(1-2):105-114.

7. Abdollahi Y, Abdullah AH, Zakaria A, Zainal Z, Masoumi HRF, Yusof NA: Photodegradation of p-cresol in Aqueous Mn (1\%)-Doped ZnO Suspensions. J Adv Oxidation Technol 2012, 15(1):146-152.

8. Guyer H: Industrial processes and waste stream management. New York: John Wiley \& Sons Inc; 1998

9. Abdollahi Y, Abdullah AH, Zainal Z, Yusof NA: Photodegradation of ocresol by ZnO under UV irradiation. J Am Sci 2011, 7(8):165-170.

10. Daneshvar N, Aber S, Seyed Dorraji M, Khataee A, Rasoulifard M: Photocatalytic degradation of the insecticide diazinon in the presence of prepared nanocrystalline $\mathrm{ZnO}$ powders under irradiation of UV-C light. Sep Purif Technol 2007, 58(1):91-98.

11. Kansal SK, Singh M, Sud D: Studies on $\mathrm{TiO}_{2} / \mathrm{ZnO}$ photocatalysed degradation of lignin. J Hazard Mater 2008, 153(1-2):412-417.

12. Akyol A, Yatmaz HC, Bayramoglu M: Photocatalytic decolorization of Remazol Red RR in aqueous ZnO suspensions. Appl Catal Environ 2004 54(1):19-24

13. Abdollahi Y, Abdullah AH, Zainal Z, Yusof NA: Photodegradation of p-cresol by Zinc Oxide under Visible Light. Int J App/ Sci Technol 2011, 1(5):99-105.

14. Abdollahi Y, Abdullah AH, Zainal Z, Yusof NA: Synthesis and characterization of Manganese doped ZnO nanoparticles. Int J Basic Appl Sci 2011, 11(4):62-69.

15. Abdollahi Y, Abdullah AH, Zainal Z, Yusof NA: Photocatalytic Degradation of p-Cresol by Zinc Oxide under UV Irradiation. Int J Mol Sci 2011, 13(1):302-315

16. Abdollahi $Y$, Zakaria A, Abdullah AH, Masoumi HRF, Jahangirian $H$, Shameli K, Rezayi M, Banerjee S, Abdollahi T: Semi-empirical study of ortho-cresol photo degradation in manganese-doped zinc oxide nanoparticles suspensions. Chem Cent J 2012, 6(1):88.

17. Abdollahi Y, Zakaria A, Matori KA, Shameli K, Jahangirian H, Abdollahi T: Interactions between photodegradation components. Chem Cent J 2012 6(1):100.
18. Khataee A, Kasiri M: Artificial neural networks modeling of contaminated water treatment processes by homogeneous and heterogeneous nanocatalysis. J Mol Catal A Chem 2010, 331(1):86-100.

19. Weisberg S: Applied linear regression. Wiley; 2005.

20. Salari D, Daneshvar N, Aghazadeh F, Khataee A: Application of artificial neural networks for modeling of the treatment of wastewater contaminated with methyl tert-butyl ether (MTBE) by $\mathrm{UV} / \mathrm{H}_{2} \mathrm{O}_{2}$ process. J Hazard Mater 2005, 125(1):205-210.

21. Aber S, Amani-Ghadim A, Mirzajani $\mathrm{V}$ : Removal of $\mathrm{Cr}(\mathrm{VI})$ from polluted solutions by electrocoagulation: Modeling of experimental results using artificial neural network. J Hazard Mater 2009, 171(1-3):484-490.

22. Hader R, Park SH: Slope-rotatable central composite designs. Technometrics 1978, 20(4):413-417.

23. Palasota JA, Deming SN: Central composite experimental designs: Applied to chemical systems. J Chem Educ 1992, 69(7):560.

24. Jorjani E, Chehreh Chelgani S, Mesroghli S: Application of artificial neural networks to predict chemical desulfurization of Tabas coal. Fuel 2008 87(12):2727-2734.

25. Sözen A, Arcaklioğlu E, Özalp M: Estimation of solar potential in Turkey by artificial neural networks using meteorological and geographical data. Energ Convers Manag 2004, 45(18-19):3033-3052.

26. Myers RH, Anderson-Cook CM: Response surface methodology: process and product optimization using designed experiments. New York: John Wiley \& Sons; 2009.

27. Hang Y, Qu M, Ukkusuri S: Optimizing the design of a solar cooling system using central composite design techniques. Energ Build 2011 43(4):988-994

28. Khataee A, Vatanpour $V$, Amani Ghadim A: Decolorization of $\mathrm{Cl}$ Acid Blue 9 solution by UV/Nano-TiO 2 , Fenton, Fenton-like, electro-Fenton and electrocoagulation processes: A comparative study. J Hazard Mater 2009, 161(2):1225-1233.

29. Fox M, Dulay M: Heterogeneous photocatalysis. Chem Rev 1993, 93(1):341-357.

30. Sanchooli M, Ghaffari Moghaddam M: Evaluation of acidity constants of anthraquinone derivatives in methanol/water mixtures using real quantum descriptors. J Chem Eng Jpn 2012, 45(6):373-379.

31. Moghaddam MG, Khajeh M: Comparison of response surface methodology and artificial neural network in predicting the microwave-assisted extraction procedure to determine zinc in fish muscles. Food Nutr 2011, 2:803-808.

32. Moghaddam MG, Ahmad FBH, Basri M, Rahman MBA: Artificial neural network modeling studies to predict the yield of enzymatic synthesis of betulinic acid ester. Electron J Biotechnol 2010, 13(3):3-4

33. Ghaffari A, Abdollahi H, Khoshayand M, Bozchalooi IS, Dadgar A, Rafiee-Tehrani $M$ : Performance comparison of neural network training algorithms in modeling of bimodal drug delivery. Int J Pharm 2006, 327(1):126-138.

34. Khare M, Nagendra SS: Artificial neural networks in vehicular pollution modelling. Springer; 2007

35. Fechine PBA, Almeida AFL, Freire FNA, Santos MRP, Pereira FMM, Jimenez $R$ Mendiola J, Sombra ASB: Dielectric relaxation of BaTiO3 (BTO)-CaCu3Ti4O12 (ССТ) composite screen-printed thick films at low temperatures. Mater Chem Phys 2006, 96(2-3):402-408.

36. Kasiri $M$, Aleboyeh $H$, Aleboyeh $A$ : Modeling and optimization of heterogeneous photo-fenton process with response surface methodology and artificial neural networks. Environ Sci Technol 2008, 42(21):7970-7975.

doi:10.1186/1752-153X-7-96

Cite this article as: Abdollahi et al:: Artificial neural network modeling of p-cresol photodegradation. Chemistry Central Journal 2013 7:96. 